\title{
Treatment of Urinary Voiding Dysfunction Syndromes With Spinal Cord Stimulation
}

\author{
Alexander E. Yakovlev, MD and Beth E. Resch, APNP
}

\begin{abstract}
This case report presents the use of spinal cord stimulation (SCS) in a patient with urinary incontinence who had previously undergone trial and implantation of InterStim therapy (Medtronic Neurological, Minneapolis, MN). The patient also experienced bilateral lower extremity pain and low back pain related to post-laminectomy syndrome. Having failed all conservative treatment, the patient underwent SCS trial and subsequent implantation. In the postoperative period using SCS therapy, the patient had excellent relief of urinary incontinence symptoms, along with relief of low back pain and bilateral lower extremity pain and was able to discontinue use of InterStim therapy. For this patient, SCS was effective in controlling the urinary voiding dysfunction symptoms, bilateral lower extremity pain and back pain. The use of SCS to treat urinary incontinence problems deserves further study to explore its therapeutic potentials.
\end{abstract}

Keywords: Dorsal column stimulation; Electric stimulation; Pain; Post-laminectomy syndrome; Sacral neuromodulation; Spinal cord stimulation; Urinary voiding dysfunction

Reprint Requests:

Alexander E. Yakovlev, MD

Comprehensive Pain Management

of the Fox Valley, SC

820 East Grant Street, Suite 335

Appleton, WI 54911

Phone: $920-733-7230$

Fax: 920-733-723

Email:dryakovlev@foxvalleypainmd.com

Received: June 2, 2009

Revised: August 21, 2009

Accepted: August 26, 2009

doi: $|0.3| 2|/ \mathrm{cmr} .20| 0.86 \mid$
$\mathrm{U}$ rinary voiding dysfunction syndromes, including urge incontinence, urinary frequency and urinary retention, affect more than 33 million people in the United States. ${ }^{1}$ Clinical presentation includes irritative symptoms of frequency and urgency with urge incontinence, obstructive symptoms including difficulty initiating and sense of incomplete emptying of the bladder, and urinary retention. ${ }^{2}$ Sacral neuromodulation is a well-established treatment option for voiding dysfunction refractory to conservative therapies, including behavioral, medical, and uro-surgical treatment.3,4 This case report presents a single patient with urinary incontinence who had previously undergone trial and implantation of InterStim therapy (Medtronic Neurological, Minneapolis, MN) (figure 1). The patient also had post-laminectomy syndrome with bilateral lower extremity pain and low back pain. Having failed all conservative treatment, she underwent spinal cord stimulation (SCS) trial and subsequent implantation. While using the SCS therapy, the patient had excellent relief of urinary incontinence symptoms and was able to discontinue use of InterStim therapy. We present the case of effective treatment of urinary voiding dysfunction symptoms, bilateral lower extremity pain and back pain with SCS.

\section{Case Report}

The patient was a 58-year-old woman $(63 \mathrm{~kg}, 159 \mathrm{~cm})$ with a history of postlaminectomy syndrome with intractable bilateral lower extremity pain and low back pain refractory to conservative therapies including caudal epidural injections, 


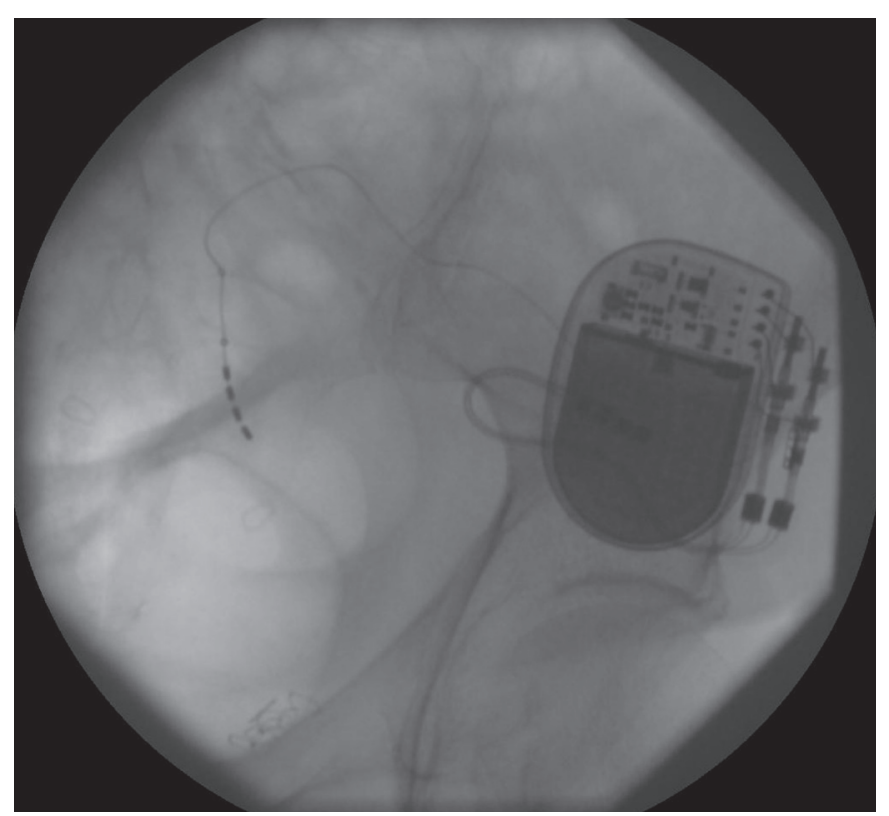

Figure 1. InterStim electrode with generator positioned over right supragluteal region.

opioid and non-opioid pain medications, behavior modification therapy and physical therapy. The patient's medical history was significant for post-laminectomy syndrome lumbar spine, chronic low back pain, left lower extremity radicular pain, hypertension, hyperlipidemia, abdominal aortic aneurysm, and urinary frequency status post-InterStim implant.

According to the patient's urology medical records and voiding diary, her urinary voiding dysfunction symptoms improved following InterStim implant as follows: urinary frequency decreased from every 1 to 2 hours to every 3 to 4 hours; pads per day decreased from 3 to 4 pads to 1 to 2 pads; nocturia episodes decreased from 4 to 5 episodes per night to zero to 1 episodes per night. She also reported a $50 \%$ improvement in symptoms of pain and urgency with voiding. According to the urologist who implanted the InterStim, she had a greater than $50 \%$ improvement in voiding parameters after implant.

The patient was on a chronic pain medication regimen, including pregablin $75 \mathrm{mg}$ every 8 hours, oxycodone/ acetaminophen $10 / 325 \mathrm{mg}$ up to 8 tablets per day. She was offered placement of SCS, and she decided to proceed with this procedure. In January 2009, the patient underwent SCS placement. The patient underwent successful trial of percutaneous placement of two 8-electrode epidural leads (Medtronic Inc, Minneapolis, MN). Epidural access was gained at the L1/L2 interspace with final leads positioned at T8-T9-T10 (figure 2). During the two day SCS trial, the patient reported a greater than $50 \%$ improvement in bilateral lower extremity and low back pain. Two weeks later the patient underwent implantation with permanent leads and a RestoreULTRA (Medtronic Inc, Minneapolis, MN) rechargeable generator. The procedure was done in ambulatory surgery, and her postoperative course was uneventful.

\section{Results}

After final implantation of SCS, the patient reported significant relief of bilateral lower extremity pain and low back pain ( $>80 \%$ reduction in visual analog score [VAS]) and was able to decrease her use of pain medications. At her 2-month follow-up, the patient reported improvement in urinary incontinence symptoms equal to results she had experienced with the implanted InterStim therapy sacral nerve stimulation. Post-operative stimulation parameters were amplitude of 3.2 volts, pulse width of 450 microseconds, and frequency of $50 \mathrm{~Hz}$. The patient used the SCS continuously and reported $100 \%$ pain relief both at rest and with activity. After implantation of SCS, the patient reported improvement in voiding dysfunction similar to that experienced with the InterStim. The patient tried using the SCS and the InterStim systems together and then each system alone over the 2-month post-op period. She experienced the same improvement in urinary voiding dysfunction symptoms whether the InterStim was on or off. She was able to discontinue use of the InterStim, and exclusively uses the SCS for effective treatment of urinary incontinence symptoms and chronic pain in the bilateral lower extremities and low back.

Other positive outcomes after SCS implant included the ability to return to social and educational activities and improved family relationships. At 6-month post-implant, the patient continues to report good pain control (VAS scores 1-3 out of 10) and improved functional status. Last SCS parameters were amplitude of 3.6 volts, pulse width of 450 microseconds, and frequency of $60 \mathrm{~Hz}$.

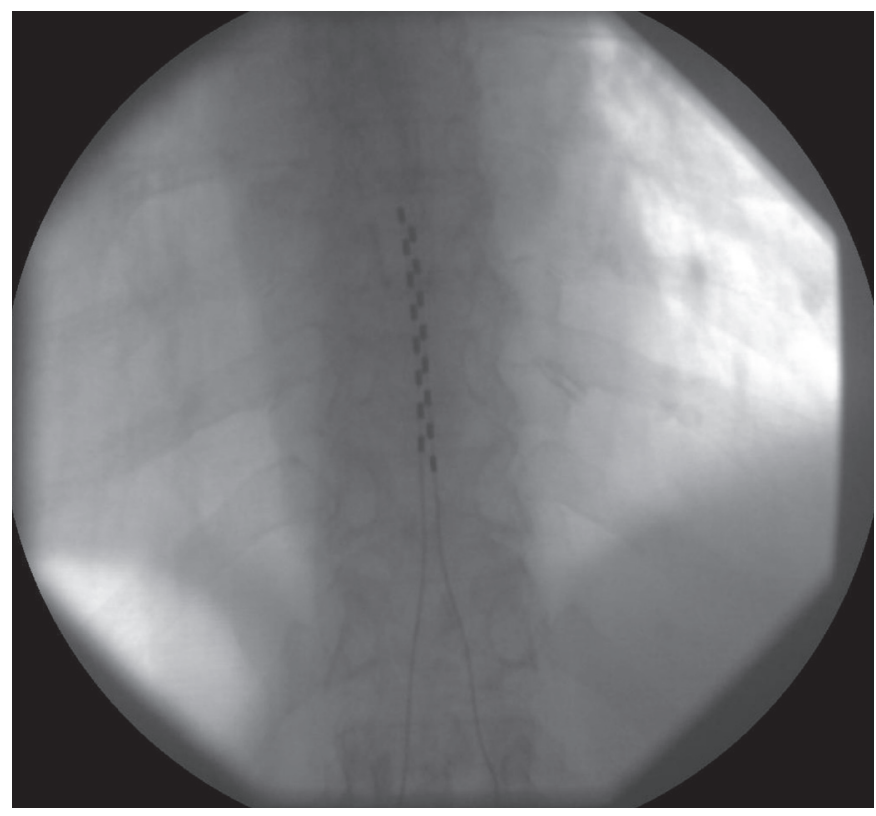

Figure 2. Lumbar epidural placement of two 8-electrode epidural leads showing the electrodes positioned at T8-T9-T10. 


\section{Discussion}

Spinal cord stimulation was first used for pain control in 1967 by neurosurgeon Dr. Norman Shealy and his colleagues. ${ }^{5}$ Spinal cord stimulation is based on the principles enunciated in the "gate-control theory" of pain proposed by Melzack and Wall in 1965.6 This theory postulates that SCS activates largediameter afferent fibers via application of an externally applied electric field that "closes the gate" to pain transmission. Spinal cord stimulation blocks pain by stimulating the dorsal columns, which inhibits transmission through the painconducting spinothalamic tract. Since its first use over three decades ago, in which electrodes were placed epidurally over the dorsal columns of the spinal cord, SCS has been further refined, and multiple studies have demonstrated its efficacy in the treatment of intractable, chronic pain with a variety of causes. ${ }^{7}$ Spinal cord stimulation has been used to successfully treat chronic pain in patients with failed back syndrome, $, 8,9$ ischemic limb pain, ${ }^{10}$ angina pectoris, ${ }^{11}$ painful peripheral neuropathies, ${ }^{12,13}$ and cancer related pain. ${ }^{14,15}$

Spinal cord stimulation may be a therapeutic alternative for patients with combined urinary dysfunction symptoms and radicular low back pain who, in the past, exhausted all available treatments or failed test stimulation before the placement of the device for InterStim therapy. Spinal cord stimulation and InterStim therapy are considered to be minimally invasive surgical interventions that have successfully positioned themselves between more conservative medical treatments and more invasive surgical procedures which may have mixed results. ${ }^{16,17}$ Spinal cord stimulation may be included in the future in the treatment algorithm of patients with complex disorders which include pain syndromes and urinary dysfunction disorders. The use of SCS to treat urinary incontinence problems deserves further study to explore its therapeutic potentials. Spinal cord stimulation is a relatively easy to perform, effective, and safe procedure. Knowledge of potential benefits of SCS can enrich the armamentarium of not just pain physicians, but also specialists who treat patients with voiding dysfunctions. It is also an excellent option for patients with co-morbidities that make them less than ideal candidates for more invasive interventions. The therapy is reversible should the voiding dysfunction alleviating effect or pain relieving effect be lost, or if voiding dysfunction symptoms resolve. For this patient, SCS is an effective treatment modality for her urinary voiding dysfunction symptoms, bilateral lower extremity pain, and back pain.

\section{References}

1. Stewart WF, Van Rooyen JB, Cundiff GW, Abrams P, Herzog AR, Corey R, Hunt TL, Wein AJ. Prevalence and burden of overactive bladder in the United States. World J Urol 2003;20:327-336.

2. Abrams P, Cardozo L, Fall M, Griffiths D, Rosier P, Ulmsten U, van Kerrebroeck P, Victor A, Wein A; Standardisation Subcommittee of the International Continence Society. The standardisation of terminology of lower urinary tract function: report from the Standardisation Sub-committee of the International Continence Society. Neurourol Urodyn 2002;21:167-178.
3. Hassouna MM, Siegel SW, Nÿeholt AA, Elhilali MM, van Kerrebroeck PE, Das AK, Gajewski JB, Janknegt RA, Rivas DA, Dijkema H, Milam DF, Oleson KA, Schmidt RA. Sacral neuromodulation in the treatment of urgency-frequency symptoms: a multi-center study on efficacy and safety. J Urol 2000;163:1849-1854.

4. Weil EH, Ruiz-Cerdá JL, Eerdmans PH, Janknegt RA, van Kerrebroeck PE. Clinical result of sacral neurmodulation for chronic voiding dysfunction using unilateral sacral foramen electrodes. World J Urol 1998;16:313-321.

5. Shealy CN. Dorsal column stimulation. Surg Neurol 1977;7:192.

6. Melzack R, Wall PD. Pain mechanisms: a new theory. Science 1965;150:971-979.

7. Cameron T. Safety and efficacy of spinal cord stimulation for the treatment of chronic pain: a 20-year literature review. J Neurosurg 2004;100 (3 Suppl Spine):254-267.

8. Struijk JJ, Holsheimer J, Spincemaille GH, Gielen FL, Hoekema $\mathrm{R}$. Theoretical performance and clinical evaluation of transverse tripolar spinal cord stimulation. IEEE Trans Rehabil Eng 1998:6:277-285.

9. Ohnmeiss DD, Rashbaum RF, Bogdanffy GM. Prospective outcome evaluation of spinal cord stimulation in patients with intractable leg pain. Spine (Phila Pa 1976) 1996;21:1344-1350.

10. Ghajar AW, Miles JB. The differential effect of the level of spinal cord stimulation on patients with advanced peripheral vascular disease in the lower limbs. Br J Neurosurg 1998;12:402-408.

11. Hautvast RW, DeJongste MJ, Staal MJ, van Gilst WH, Lie KI. Spinal cord stimulation in chronic intractable angina pectoris: a randomized, controlled efficacy study. Am Heart J 1998;136:1114-1120.

12. Kumar K, Toth C, Nath RK. Spinal cord stimulation for chronic pain in peripheral neuropathy. Surg Neurol 1996;46:363-369.

13. Tesfaye S, Watt J, Benbow SJ, Pang KA, Miles J, MacFarlane IA. Electrical spinal-cord stimulation for painful diabetic peripheral neuropathy. Lancet 1996;348:1698-1701.

14. Cata JP, Cordella JV, Burton AW, Hassenbusch SJ, Weng HR, Dougherty PM. Spinal cord stimulation relieves chemotherapy-induced pain: a clinical case report. J Pain Symptom Manage 2004;27:72-78.

15. Yakovlev AE, Ellias Y. Spinal cord stimulation as a treatment option for intractable neuropathic cancer pain. Clin Med Res 2008;6:103-106.

16. Hohenfellner M, Linn J, Hampel C, Thuroff JW. Surgical treatment of interstitial cystitis. In: Sant GR, ed. Interstitial cystitis. Philadelphia, PA: Lippincott-Raven;1997. 223-233.

17. Baskin LS, Tanagho EA. Pelvic pain without pelvic organs. J Urol 1992;147:683-686.

\section{Author Affiliations}

Alexander E. Yakovlev, MD and Beth E. Resch, APNP

Comprehensive Pain Management of the Fox Valley, SC

820 East Grant Street Suite 335

Appleton, Wisconsin 